\title{
La alteración de términos municipales en la reforma local de 2013: crónica de un fracaso anunciado ${ }^{1}$
}

\section{The alteration of municipal terms in the local reform of 2013: chronicle of an announced failure}

\author{
Eloísa Carbonell Porras \\ Universidad de Jaén \\ eloisa.carbonell@ujaen.es
}

\section{NOTA BIOGRÁFICA}

Catedrática de Derecho Administrativo en la Universidad de Jaén. Con anterioridad ha sido profesora en las Universidades de Córdoba y Complutense de Madrid. Sus líneas de investigación fundamentales son el Derecho Local y el Derecho del Transporte.

\begin{abstract}
RESUMEN
La reforma de la legislación básica de régimen local operada por la Ley 27/2013, de 27 diciembre, de Racionalización y Sostenibilidad de la Administración Local, ha incidido en la planta municipal para intentar corregir los problemas de minifundismo en un doble plano: por un lado, se han endurecido los requisitos para crear municipios por segregación; y, por otro, se aprueban medidas de fomento de la fusión de municipios, regulando el convenio de fusión voluntaria. Estas modificaciones delimitan el objeto de este estudio que analiza los principales problemas jurídicos que la interpretación de estos cambios suscita así como sus consecuencias reales. Sobre su base, se concluye que, aunque los cambios sí son relevantes para impedir nuevos municipios, tienen una eficacia muy limitada para reducir los municipios pequeños existentes.
\end{abstract}

\section{PALABRAS CLAVE}

Derecho local; términos municipales; fusión de municipios.

\begin{abstract}
The reform of the basic legislation of the local regime operated by Law 27/2013, of December 27, on Rationalization and Sustainability of Local Administration has affected the municipal structure in order to try to correct the problems of small municipalities in a double sense: on the one hand, the requirements to create municipalities by segregation have been hardened; and, on the other, measures to promote the merger of municipalities have been approved, by regulating the voluntary merger agreement. These modifications delimit
\end{abstract}

\footnotetext{
1 Este trabajo constituye mi colaboración para la obra Estudios de Derecho Público. Libro Homenaje al Profesor Luciano Parejo Alfonso y ha sido realizado en el marco del Proyecto I+D+i del Plan Nacional, Las Entidades locales, sus relaciones y competencias. Realidad, efectos y consecuencias de la racionalización y sostenibilidad financiera en clave nacional y europea (DER2016-74843-C31-R), del que soy Investigadora Principal, que se desarrolla en el Grupo de Investigación del Plan Andaluz de Investigación, Desarrollo e Innovación (PAIDI) SEJ-317, "El Derecho Público y la crisis institucional y económica". También deben tenerse en cuenta el Grupo de Excelencia de la Universidad Rey Juan Carlos, "Derecho y política económica” (GEDPE), y el Grupo de Investigación de la Universidad Complutense de Madrid 931089, "Las transformaciones del Estado y la autonomía local: organización institucional, servicios públicos y democracia participativa", en los que colaboro como miembro externo.
} 
the object of this study that analyzes the main legal problems that the interpretation of these changes imply as well as their real consequences. On its basis, it is concluded that, although the changes are relevant to prevent new municipalities, they have a very limited effectiveness in reducing the existing small municipalities.

\title{
KEYWORDS
}

Local regime; municipal terms; merger of municipalities.

\author{
SUMARIO \\ I. UNA AMBICIOSA REFORMA DE LIMITADA EFICACIA. II. LA MODIFICACIÓN DEL ARTÍCULO 13 LBRL \\ EN GENERAL. III. LOS NUEVOS REQUISITOS PARA LA CREACIÓN DE MUNICIPIOS POR SEGREGA- \\ CIÓN DE UN NÚCLEO DE POBLACIÓN. IV. LA FUSIÓN VOLUNTARIA DE MUNICIPIOS: A) GENERALIDA- \\ DES. B) MUNICIPIOS SUSCEPTIBLES DE FUSIONARSE. C) NATURALEZA DEL CONVENIO DE FUSIÓN \\ Y SU RELACIÓN CON EL PROCEDIMIENTO GENERAL PARAALTERAR LOS TÉRMINOS MUNICIPALES. \\ D) CONSECUENCIAS DE LA FUSIÓN. D) LAS MEDIDAS DE FOMENTO DE LA FUSIÓN. E) LA PROPUES- \\ TA DE FUSIÓN DEL ARTÍCULO 116. BIS LBRL. V. UNA REFLEXIÓN FINAL. VI. BIBLIOGRAFÍA.
}

\section{UNA AMBICIOSA REFORMA DE LIMITADA EFICACIA}

La Ley 27/2013, de 27 diciembre, de racionalización y sostenibilidad de la Administración Local (en adelante, LRSAL) llevó a cabo una profunda modificación de la Ley 7/1985, de 2 de abril, reguladora de las bases de régimen local (en adelante, LBRL), directamente relacionada con la reforma del artículo 135 de la Constitución y el programa de medidas para reestructurar nuestra organización pública del conocido informe CORA. Con esta idea los objetivos básicos según el preámbulo de la LRSAL son «clarificar las competencias municipales para evitar duplicidades con las competencias de otras Administraciones de forma que se haga efectivo el principio "una Administración, una competencia", racionalizar la estructura organizativa de la Administración local de acuerdo con los principios de eficiencia, estabilidad y sostenibilidad financiera, garantizar un control financiero y presupuestario más riguroso y favorecer la iniciativa económica privada evitando intervenciones administrativas desproporcionadas». Su aprobación fue controvertida, discutiéndose en todos los foros y desde todas las perspectivas posibles. Pretendía reformar nuestras Administraciones locales desde la óptica de la estabilidad presupuestaria y la sostenibilidad financiera, que constituyó su fundamento inicial, pero afecta con diverso alcance y sentido a todo el régimen local. Sin embargo, por razones distintas, las consecuencias no han sido las esperadas: las Comunidades Autónomas reaccionaron con rapidez para evitar su aplicación²; la doctrina se mostró sumamente crítica, cuestionando su constitucionalidad y su eficacia en la consecución de esos objetivos, poniendo de manifiesto sus deficiencias técnicas que, en cierta medida, abrieron cauces para realizar interpretaciones conforme la Constitución pero en sentido diferente del pretendido por el legislador ${ }^{3}$; el Tribunal Constitucional ya ha resuelto los diversos recursos de inconstitucionalidad, anulando algunos

\footnotetext{
2 Puede verse, entre otros, A. GALÁN GALÁN, "La aplicación autonómica de la Ley de Racionalización y Sostenibilidad de la Administración Local", en Revista de Estudios de la Administración Local y Autonómica, núm. extraordinario 2015; o, J. TEJEDOR BIELSA, "El desarrollo autonómico de la reforma local de 2013. Entre la rebelión y el pragmatismo", en Los retos del gobierno local tras la reforma de 2013, 2015, pág. 81 y ss.

${ }^{3}$ EI VIII Congreso de la Asociación Española de Profesores de Derecho Administrativo, celebrado en Alicante, los días 8 y 9 de febrero de 2013, ya cuestionaba algunas de las modificaciones que se pretendían introducir y así se recoge en las actas publicadas en La planta del Gobierno Local, coordinadas por J. J. DíEZ SÁNCHEZ, Fundación Democracia y Gobierno Local, Barcelona, 2013. También pueden verse las obras colectivas Reforma del Régimen Local. La Ley de Racionalización y Sostenibilidad de la Administración Local: veintitrés estudios, 2014; La reforma de 2013 del régimen local español, 2014; La reforma del régimen local, 2014; Sostenibilidad financiera y Administración local. Un estudio comparado, 2014; La reforma del Régimen Jurídico de la Administración Local. El nuevo marco regulatorio de la Ley de racionalización y sostenibilidad de la Administración Local, 2014; Los retos del gobierno local tras la reforma de 2013, 2015; Ley de racionalización y sostenibilidad de la Administración Local. Estudio sobre la aplicación de la Ley 27/2013, de 27 de diciembre, 2015; Análisis de las repercusiones de la reforma local sobre la organización, competencias y servicios de las entidades locales, 2015; y, La racionalización de la organización administrativa local: las experiencias española, italiana y portuguesa, 2015; Comentarios a la Ley 27/2013, de 27 de diciembre, de Racionalización y Sostenibilidad de la Administración local; así como los números monográficos del Anuario del Gobierno Local, 2013, Racionalización y sostenibilidad de la Administración Local: ¿es esta la reforma?, 2013; y ¿Un nuevo gobierno local en España? La reforma de la Administración local en la Ley 27/2013, 2012; de Cuadernos
} 
REALA. Nueva Época - N. 9 9, Abril 2018 - ISSN: 1989-8975 - DOI: 10.24965/reala.v0i9.10513 - [Págs. 5-21]

La alteración de términos municipales en la reforma local de 2013: crónica de un fracaso anunciado

Eloísa Carbonell Porras

de sus artículos e interpretando otros conforme a la Constitución ${ }^{4}$. Por todo esto, la efectividad de la reforma cuatro años después ha sido limitada con carácter general ${ }^{5}$. Tampoco son muchos los logros conseguidos en la pretensión de incidir en el minimunicipalismo como seguidamente se pone de manifiesto.

\section{LA MODIFICACIÓN DEL ARTÍCULO 13 LBRL EN GENERAL}

Como es sabido, la reforma ambiciona modificar la estructura organizativa local desde la óptica de la racionalización y la sostenibilidad financiera. En la materialización de este objetivo destaca, sin duda, la supresión de las Entidades locales de ámbito territorial inferior al Municipio que podían reconocer las Comunidades Autónomas según disponía la letra a) del apartado 2 del artículo 3 LBRL, que ha sido suprimida ${ }^{6}$. En relación con las Entidades Locales constitucionalmente garantizadas, la LRSAL pretendería incidir en la planta municipal modificando al efecto el artículo 13 LBRL sobre los términos municipales, por un lado, y, por otro lado, reforzando la posición institucional de las Diputaciones Provinciales según confiesa expresamente el preámbulo de la LRSAL. De esta segunda cuestión he tenido ocasión de ocuparme con cierto detalle para concluir que, tras la reforma, también las comarcas -y otros entes supramunicipales- pueden considerarse «entidades equivalentes» a las Diputaciones provinciales (como desde el principio han sido las Comunidades Autónomas uniprovinciales, las Diputaciones Forales vascas y los Cabildos y Consejos Insulares), de modo que la consecuencia final podría suponer lo contrario al pretendido reforzamiento de las Diputaciones ${ }^{7}$. Ahora se analiza la nueva redacción del artículo 13 LBRL, que establece la legislación estatal básica en relación con la alteración de los términos municipales ${ }^{8}$.

de Derecho Local, La revisión del Gobierno y la Administración local en la Ley 27/2013, núm. 34, 2014; de la Revista de Estudios de la Administración Local y Autonómica. Nueva Época. núm. extraordinario, 2015; y de la Revista de Estudios Locales, núm. extraordinario 169, Análisis de la Ley 27/2013, de Racionalización y Sostenibilidad de la Administración Local. También las monografías M. MEDINA GUERRERO, La reforma del régimen local, 2014; L. MELLADO RUIZ, Génesis y realidad de la Ley 27/2013, de 27 de diciembre, de Racionalización y Sostenibilidad de la Administración Local: ¿una nueva reforma económica local?, 2014.

Como tuve ocasión de señalar en E. CARBONELL PORRAS, "Sobre la reforma local y las competencias municipales propias", en Revista Vasca de Administración Pública, núms. 99/100, 2014, págs. 765-766, además de las dudas sobre la constitucionalidad de algunos preceptos o la necesidad de realizar interpretaciones conforme a la Constitución de la misma, la LRSAL es deficiente técnicamente; incurre en varias contradicciones e incongruencias que se aprecian con más claridad cuando se maneja un texto consolidado de la LBRL, pues no siempre tuvo en cuenta los preceptos que no eran modificados; y se acrecientan con la lectura de las disposiciones adicionales y transitorias de la propia LRSAL.

${ }_{4}^{4}$ Concretamente se trata de la STC $41 / 2016$ de 3 marzo, que resuelve el recurso de inconstitucionalidad planteado por la Asamblea de Extremadura; la STC 111/2016, de 9 de junio, el interpuesto por la Junta de Andalucía; la STC 168/2016, de 6 de octubre, el del Principado de Asturias; la STC 180/2016, de 20 de octubre, el del Parlamento de Navarra; la STC 44/2017, de 27 de abril, el de los Diputados integrantes de diversos grupos parlamentarios; la STC 45/2017, de 27 de abril, el interpuesto por el Parlamento de Andalucía; la STC 54/2017, de 11 de mayo, el del Parlamento de Cataluña; la STC 93/2017, de 6 de julio, el de la Generalitat de Cataluña; la STC 101/2017, de 20 de julio, el del Gobierno de Canarias; y la STC 107/2017, de 21 de septiembre, que resuelve el conflicto en defensa de la autonomía local planteado por 2.393 municipios. Puede verse, entre otros, L. MEDINAALCOZ, "La distribución de competencias entre el Estado y las Comunidades Autónomas a la luz de las sentencias constitucionales sobre la reforma local de 2013", y R. GRACIA RETORTILLO, "La LRSAL ante el Tribunal Constitucional: la afectación a la autonomía local", ambos en Anuario del Gobierno Local 2015/2016, pág. 189 y ss. y 2.225 y ss., respectivamente; A. BAYONA I ROCAMORA, "La Ley de Racionalización y Sostenibilidad de la Administración Local y el Tribunal Constitucional: comentarios a las primeras sentencias", en Cuadernos de Derecho Local, núm. 4, 2017, pág. 284 y ss.; C. PADRÓS REIG, "El examen de la constitucionalidad de la reforma local de 2013", en Revista General de Derecho Administrativo núm. 46, 2017; J. M. DÍAZ LEMA, "La STC 041/2016: aval del Tribunal Constitucional a las medidas relativas a la planta local y la reordenación de las competencias locales de la Ley 27/2013, de 27 de diciembre", en Revista Española de Derecho Administrativo, núm. 181, 2016, pág. 351 y ss.; L. MARTíN REBOLLO y J. M. ALEGRE ÁVILA, "Las competencias locales en la STC 41/2016, de 3 de marzo", en Los retos del Estado y la Administración en el siglo XXI. Libro homenaje al profesor Tomás de la Quadra-Salcedo Fernández del Castillo, 2017, pág. 2.015 y ss.; o A. BOIX PALOP, "El régimen local tras el fracaso de la reforma 2013", en El Cronista del Estado Social y Democrático de Derecho, núm. 68, 2017, pág. 24 y ss.

${ }_{5}^{5}$ Pueden verse las reflexiones generales de L. MELLADO RUIZ, "Crisis económica y Administración local" en Crisis económica y Derecho Administrativo. Una visión general y sectorial de las reformas implantadas con ocasión de la crisis económica, 2016, pág. 95 y ss. También F. VILLAR ROJAS, "Razones y contradicciones de la Racionalización y Sostenibilidad de la Administración Local" en La administración al día, 18 de julio de 2014; o L. PAREJO ALFONSO, "Algunas reflexiones sobre el impacto de la Ley 27/2013, de 27 de diciembre, sobre el modelo de autogobierno local” en Cuadernos de Derecho local núm. 34, 2015, pág. 15.

${ }^{6}$ En consecuencia también se elimina el artículo 45 LBRL que las regulaba. De todo ello se ha ocupado con detenimiento R. PIZARRO NEVADO, "Entidades y «entes» de ámbito territorial inferior al municipio tras la reforma local de 2013", en Revista de Estudios de la Administración Local y Autonómica núm. 8, 2017, pág. 49 y ss.

7 Vid. E. CARBONELL PORRAS, "Replanteamiento sobre las provincias: del pretendido reforzamiento de su posición institucional a una posible mutación constitucional”, en Anuario del Gobierno Local 2015/16, 2016, pág. 105 y ss.

${ }^{8}$ Como es sabido, las Comunidades Autónomas asumieron la competencia relativa a las alteraciones de los términos municipales de su territorio con apoyo en el artículo 148.1. 2. ${ }^{a}$ de la Constitución. Sobre el reparto de competencias en esta materia, puede verse E. CARBONELL PORRAS, "La planta local: análisis general y perspectivas de reforma", en La planta..., cit., pág. 28 y ss. 
REALA. Nueva Época - N. 9 9, Abril 2018 - ISSN: 1989-8975 - DOI: 10.24965/reala.v0i9.10513 - [Págs. 5-21]

La alteración de términos municipales en la reforma local de 2013: crónica de un fracaso anunciado

Eloísa Carbonell Porras

Curiosamente y a pesar de la insistencia doctrinal en la necesaria corrección de nuestra planta municipal, ninguno de los borradores de anteproyectos de la reforma contemplaban modificar el artículo 13 LBRL, aunque sí lo hace el Proyecto de Ley ${ }^{9}$. Los cambios tienen diferente alcance: en primer lugar, se exige el informe de la Administración que ejerza la tutela financiera en todos los procedimientos de alteración de términos municipales ( apartado $1 .^{\circ}$ ); en segundo lugar, se endurecen las condiciones para la creación de nuevos municipios (apartado $2 .^{\circ}$ ); y, en tercer lugar, se desarrollan las medidas de fomento de la fusión de los municipios que desde 1985 preveía el apartado $3 .^{\circ}$, introduciendo al efecto los nuevos apartados $4 .^{\circ}, 5 .^{\circ}$ y $6 . .^{\circ}$. Esta modificación suscita diversas cuestiones de interés que no han pasado desapercibidas para la doctrina ${ }^{10}$.

Seguidamente se analizan las novedades más relevantes del nuevo artículo 13 LBRL respecto de la creación de nuevos municipios, que puede producirse por segregación de un núcleo de población en el supuesto previsto en el apartado 2, o por fusión de municipios preexistentes en los apartados 4 a 6 . Se trata, por tanto, de dos supuestos diferentes pues, en el primer caso, nacerá un nuevo municipio, manteniéndose aquél del que se segrega, mientras que en el segundo, sí se reducirá el número de municipios al suprimirse los fusionados. Pero en los dos supuestos se trata de alterar los términos municipales y, en consecuencia,

9 El grupo de colaboración interadministrativa del Instituto Nacional de Administración Pública formuló una propuesta de modificación del articulado LBRL (versión 1.2 de 25 de mayo de 2012) que no afectaba al artículo 13 de la misma, aunque en las cuestiones pendientes se incluía la relativa a la alteración del términos municipales planteándose la posibilidad de añadir al apartado 2 del artículo 13 LBRL la prohibición de que el municipio resultante de una segregación pudiera tener menos de 20.000 habitantes. Tampoco el informe ejecutivo de la Comisión para la Reforma de las Administraciones Públicas (CORA), disponible en http://www.sefp.minhafp.gob.es/ web/areas/reforma_aapp/actuaciones.html, presentado al Consejo de Ministros del 21 de junio de 2013, págs. 18-19, hace referencia a concretas medidas de corrección de los términos municipales. Los diversos anteproyectos de ley de 13 de julio, de 14 de noviembre y de 22 de diciembre de 2012, así como los de 4 y 18 de febrero y 21 de mayo de 2013 no prevén ninguna reforma del artículo 13 LBRL. Es el Proyecto de Ley publicado en el Boletín Oficial de las Cortes generales. Congreso de los Diputados de 6 de septiembre de 2013, núm. 58-1 el que ya introduce la modificación que coincide con la definitivamente aprobada.

No obstante, el anteproyecto de 4 de febrero de 2013 incorporaba a la LBRL un nuevo artículo 61 bis que determinaba la extinción de los municipios con población inferior a 5.000 habitantes si sus órganos de gobierno habían sido disueltos por su persistencia en el incumplimiento de la Ley Orgánica 2/2012, de 27 de abril, de Estabilidad Presupuestaria o concurrían ciertas circunstancias (evaluación negativa de los servicios mínimos, remanentes de tesorería para gastos generales negativos...). Esta opción fue pronto abandonada pues con el anteproyecto de 18 de febrero de 2013 el precepto sólo contemplaba la intervención de estos municipios. La versión de 21 de mayo de 2013 también acaba con esta idea, limitándose a remitir a las medidas coercitivas previstas en la Ley Orgánica 2/2012, que tampoco está presente en el Proyecto de Ley.

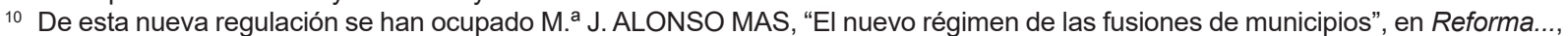
cit., pág. 297 y ss.; J. J. DÍEZ SÁNCHEZ, "Estrategias para ganar tamaño en la gestión administrativa tras la reforma de 2013", en LoS

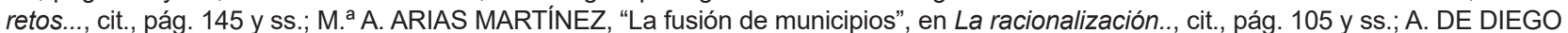
GÓMEZ, "Las fusiones de ayuntamientos", en La reforma..., cit., pág. 301 y ss., y "La fusión de ayuntamientos en la Ley 27/2013, de Racionalización y Sostenibilidad de la Administración Local", en El Consultor de los Ayuntamientos y de los Juzgados, núm. 5, 2014, pág. 546 y ss.; J. M. DÍAZ LEMA, "La proyección del principio de sostenibilidad financiera sobre el marco competencial y la reordenación del «mapa» local (Ley 27/2013, de 27 diciembre)", en Sostenibilidad financiera..., cit., pág. 101 y ss.; E. JIMÉNEZ BLANCO, "La fusión de municipios en la Ley de racionalidad y sostenibilidad de la Administración Local", en Análisis... cit.; M. ALMEIDA CERREDA, "Un nuevo instrumento para el redimensionamiento de la planta municipal española: el convenio de fusión entre ayuntamientos", en Istituzioni del federalismo: rivista di studi giuridici e politici, núm. 2, 2015, pág. 331 y ss.; y "La planta local a pequeña escala: municipios y entidades locales menores", en Cuadernos de Derecho Local, núm. 35, 2014, pág. 7 y ss.; también M. ALMEIDA CERREDA, "La fusión convencional de municipios: una institución introducida por la Ley 27/2013, de 27 de diciembre, y consagrada por la Sentencia del Tribunal Constitucional 41/2016, de 3 de marzo", y D. DE SANTIAGO IGLESIAS, "Debate sobre la fusión de municipios en España: balance histórico y estado actual de la cuestión", ambos en Estudos em homenagem ao Professor Doutor António Cândido de Oliveira, 2017; F. A. CASTILLO BLANCO, "La reforma de los Gobiernos Locales en España. ¿una oportunidad perdida para lograr una planta local competitiva y sostenible?", en Memorial para la reforma del Estado. Estudios en homenaje al profesor Santiago Muñoz Machado, 2017, II, pág. 1947 y ss.; A. CALONGE VELÁZQUEZ, "La fusión de municipios, único instrumento de la Ley 27/2013, de 27 de diciembre, de racionalización y sostenibilidad de la Administración Local para la modificación de la planta municipal: una oportunidad perdida", en Revista de Estudios de la Administración Local y Autonómica núm. extraordinario enero 2015, pág. 6 y ss.; J. AMENÓS ÁLAMO, "El elemento territorial del municipio en la Ley 27/2013, de Racionalización y Sostenibilidad de la Administración Local", en Anuario de Gobierno local 2013, 2014, pág. 49 y ss.; L. M. ARROYO YANES, "La creación de municipios en el nuevo derecho de la Administración Local", y F. J. SANZ LARRUGA, "De la segregación a la fusión de municipios en España", ambos en Libro homenaje al profesor Rafael Barranco Vela, 2014, págs. 2177 y ss., y 2403 y ss., respectivamente; A. PALOMAR OLMEDA, "La supresión-fusión de municipios", en Cuadernos de Derecho Local núm. 37, 2015 pág. 225 y ss.; M. PONS-PORTELLA, "La población mínima de los nuevos municipios: estado de la cuestión tras la Ley de Racionalización y Sostenibilidad de la Administración Local", en Revista de Estudios de la Vida Local y Autonómica núm. 5, 2016; F. J. GRACIA HERRERO, "La racionalización de la estructura organizativa en los pequeños municipios tras la reforma local", en El Consultor de los Ayuntamientos y de los Juzgados, núm. 5, 2014, págs. 529 y ss. y, J. ÁLVAREZ MONTOTO, "La Incidencia de la Ley de Racionalización y Sostenibilidad de la Administración Local en la planta local española. La fusión voluntaria de municipios”, en Revista de Estudios Locales. Cunal, núm. 173, 2014, pág. 12 y ss. Desde una perspectiva más amplia, F. J. DURÁN GARCíA, La fusión de municipios como estrategia, 2016, y "La fusión coactiva de municipios en España: principios, estrategia y resultados", en El Cronista del Estado Social y Democrático de Derecho, núm. 57, 2016, pág. 44 ss; así como E. MARÍNEZ DE LA CASA RODRÍGUEZ, "Vetos y resistencias en el fracaso de la reforma de la planta local en España", en Revista Española de Estudios de la Administración Local y Autonómica, núm. 5, 2015, p. 120 ss. 
deberá estarse a lo previsto con carácter general en el apartado 1 de este artículo 13 LBRL que, como es sabido, remite a la legislación de las Comunidades Autónomas la regulación, dentro del respeto a unos trámites básicos (audiencia a los municipios afectados, dictamen del Consejo de Estado u órgano consultivo autonómico, y puesta en conocimiento de la Administración del Estado) entre los que ahora se incluye un nuevo informe, el de la Administración que ejerza la tutela financiera ${ }^{11}$. Se trata, por tanto, de una reforma limitada, que no incide radical y drásticamente en la planta municipal ${ }^{12}$.

En todo caso, y sin perjuicio de ulteriores precisiones, debe tenerse en cuenta que el Tribunal Constitucional ha considerado que la nueva regulación no invade las competencias autonómicas en materia de alteración de términos municipales, siendo manifestación de las competencias del Estado derivadas de los apartados $14 .^{\circ}$ y $18 .^{\circ}$ del artículo 149.1 . de la Constitución.

\section{LOS NUEVOS REQUISITOS PARA LA CREACIÓN DE MUNICIPIOS POR SEGREGACIÓN DE UN NÚCLEO DE POBLACIÓN}

Desde 1985 la legislación estatal básica ha supeditado la creación de nuevos municipios a la existencia de un núcleo de población territorialmente diferenciado, que constituye el presupuesto previo necesario, y a la acreditación de que no se producirá una disminución en la calidad de los servicios que se venían prestando y que el nuevo municipio contará con recursos suficientes para el cumplimiento de las competencias municipales. Ahora el artículo 13. 2 LBRL exige dos nuevos requisitos: que el núcleo de población territorialmente diferenciado cuente con al menos 5.000 habitantes y que los municipios resultantes sean financieramente sostenibles. Estos requisitos son exigibles a la creación de un nuevo municipio por segregación de ese núcleo de población diferenciada, pero no cuando el nuevo municipio es consecuencia de un proceso de fusión. Precisamente uno de los supuestos previstos en la legislación autonómica para fusionar municipios es que separadamente carezcan de capacidad o recursos suficientes para atender los servicios municipales obligatorios.

El Tribunal Constitucional ha rechazado la pretendida inconstitucionalidad del precepto afirmando que «la exigencia de que se creen nuevos municipios sólo cuando resulten financieramente sostenibles (apartado 2), si no deriva directamente de los artículos 31.2, 103.1 y 135 de la Constitución, entra dentro, sin lugar a dudas, de la competencia estatal para diseñar el modelo municipal español; exactamente igual la fijación de mínimos poblacionales: el Estado puede desarrollar un modelo municipal al amparo del art. 149.1.18 de la Constitución "basado en mayores exigencias de población y territorio", si lo considera "necesario para garantizar la viabilidad del ejercicio de las competencias que se atribuyen a los municipios y con ello su autonomía" ${ }^{13}$. La constitucionalidad del nuevo artículo 13.2 LBRL ha sido reafirmada, además, en la STC 108/2017, de 21 de septiembre, que estima el recurso de inconstitucionalidad interpuesto por el Presidente del Gobierno contra la Ley del Parlamento de Cataluña 8/2015, de 10 de junio, de creación del municipio de Medinyà, que es declarada inconstitucional y consiguientemente nula por violación de la legislación estatal básica al crear un nuevo municipio que sólo cuenta con 866 habitantes, según reconoce expresamente su preámbulo ${ }^{14}$.

Hasta ahora han sido las Comunidades Autónomas las que han fijado la población mínima exigible al núcleo territorialmente diferenciado que aspira a convertirse en un nuevo municipio, generalmente inferior a los 5.000 habitantes ${ }^{15}$. La entrada en vigor de la reforma provoca la inaplicación de forma inmediata y permanente de la legislación autonómica que contradiga la nueva regulación básica ${ }^{16}$. Además, hay que de-

11 Corresponderá a la Comunidad Autónoma si ha asumido estatutariamente la tutela financiera o al Ministerio de Hacienda, sin perjuicio de las especialidades forales y, como nada ha dispuesto la Ley, el informe se entenderá no vinculante de acuerdo con el artículo 80. 1 de la Ley 39/2015, de 1 de octubre de Procedimiento Administrativo Común de las Administraciones Públicas. En el mismo sentido, M. ${ }^{a}$ A. ARIAS MARTÍNEZ, "La fusión...", cit., pág. 117.

12 Puede verse L. COSCULLUELA MONTANER, "Reforma de la Administración Local. Una oportunidad de modificar la planta municipal que no puede perderse", en Revista Española de Derecho Administrativo, núm. 157, 2013, pág. 11 y ss.

${ }_{13}$ Fundamento Jurídico 6. ${ }^{\circ}$, apartado b) de la STC 41/2016, a la que remiten las SSTC 111/2016, 180/2016, 44/2017, 54/2017, 93/2017 y 101/2017.

14 Vid. R. PIZARRO NEVADO, “Entidades...”, cit., pág. 71.

15 De este dato se ha ocupado M. PONS-PORTELLA, "La población...", cit., que pone de relieve la cifra oscila entre los 500 habitantes en la Rioja hasta los 6.000 de las Islas Baleares. Salvo Canarias y Galicia que también exigen 5.000 habitantes, las demás prevén inferior población o no han fijado un mínimo. L. M. ARROYO YANES, "Incidencia general...", cit., pág. 956 cuestiona que el legislador estatal básico no haya tenido en cuenta los requisitos de población previstos en la legislación autonómica.

${ }_{16}$ Como es sabido, la aprobación de normas estatales básicas y sus efectos la legislación autonómica preexistente que quedaría desplazada, derogada o devendría inconstitucional es un tema ampliamente debatido del que, por razones obvias, se prescinde. Un 
REALA. Nueva Época - N. 9 9, Abril 2018 - ISSN: 1989-8975 - DOI: 10.24965/reala.v0i9.10513 - [Págs. 5-21]

La alteración de términos municipales en la reforma local de 2013: crónica de un fracaso anunciado

Eloísa Carbonell Porras

ducir que tampoco podría producirse la creación de un nuevo municipio si aquel del que se segregara viera reducida su población por debajo de dicha cifra ${ }^{17}$. Por otra parte, los municipios afectados por el proceso de alteración deben ser financieramente sostenibles, lo que, en principio, remite al cumplimiento de los principios de la Ley Orgánica 2/2012, de 27 de abril, de estabilidad presupuestaria y sostenibilidad financiera; concretamente a su artículo 4 , dedicado al principio de sostenibilidad financiera, que puntualiza en su apartado $2 .^{\circ}$, que «se entenderá por sostenibilidad financiera la capacidad para financiar compromisos de gasto presentes y futuros dentro de los límites de déficit, deuda pública y morosidad de deuda comercial conforme a lo establecido en esta Ley, la normativa sobre morosidad y en la normativa europea» ${ }^{18}$.

En otro plano, debe notarse que el recelo de las Comunidades Autónomas ante una reforma local que iba a incidir en la planta municipal provocó, como ha señalado Pizarro Nevado, que se activaran los procedimientos de creación de nuevos municipios, generalmente con población inferior a los 5.000 habitantes, incluso después de la entrada en vigor de la reforma, el 31 de diciembre de $2013^{19}$. Así ha sucedido particularmente en la Comunidad Autónoma de Andalucía ${ }^{20}$. La creación de estos nuevos municipios se produce por segregación de las entidades Inframunicipales creadas conforme a la anterior normativa autonómica ${ }^{21}$ y la inaplicación de

detenido análisis de esta cuestión, con la bibliografía más relevante, lo ha realizado M. REBOLLO PUIG, "En busca de la prevalencia perdida", en Memorial para la reforma del Estado. Estudios en homenaje al profesor Santiago Muñoz Machado, 2017, pág. 1.581 y ss., al que remitimos. En esa misma obra colectiva A. M. GONZÁLEZ SANFIEL, "Desplazamiento versus inconstitucionalidad sobrevenida (la lucha encubierta entre la jurisdicción ordinaria y el Tribunal Constitucional”, pág. 1.617, analiza la jurisprudencia constitucional al respecto. La STC 102/2016, de 25 de mayo, dictada en relación con el cambio en la mayoría exigida para alterar los términos municipales en la legislación estatal básica invoca la cláusula de prevalencia del artículo 149. 3 de la Constitución, para sostener que se produce la inaplicación de la norma autonómica que deviene contraria a una norma estatal básica posterior.

17 En el mismo sentido, M. ${ }^{a}$ J. ALONSO MAS, "El nuevo...", cit., págs. 306-307.

18 El artículo 4 de la Ley Orgánica aclara que la sostenibilidad de la deuda comercial, se producirá cuando el período medio de pago a los proveedores no supere el plazo máximo previsto en la normativa sobre morosidad y que para el cumplimiento del principio de sostenibilidad financiera las operaciones financieras se someterán al principio de prudencia financiera. En todo caso, la Ley Orgánica en su conjunto está orientada a garantizar ese principio. A estos efectos es relevante el artículo 6, relativo al principio de transparencia, que dispone que la contabilidad de las Administraciones Públicas, así como sus Presupuestos y liquidaciones, «deberán contener información suficiente y adecuada que permita verificar su situación financiera, el cumplimiento de los objetivos de estabilidad presupuestaria y de sostenibilidad financiera y la observancia de los requerimientos acordados en la normativa europea en esta materia». En el mismo sentido, M. ${ }^{a}$ J. ALONSO MAS, "EI nuevo...", cit., págs. 306-307; M. ${ }^{a}$ A. ARIAS MARTíNEZ, "La fusión...", cit., pág. 118; y M. ALMEIDA CERREDA, "La planta local...", cit., pág. 9.

19 Vid. R. PIZARRO NEVADO, “Entidades...", cit., págs. 70-71. También Miquel PONS-PORTELLA, “La población...”, cit., y D. Santiago Iglesias, "Debate...", cit., pág. 233.

Así, antes de la aprobación de la reforma, en Extremadura se han creado por segregación de entidades locales menores los municipios de Tiétar y Pueblonuevo de Miramontes segregado del de Tayuela, provincia de Cáceres, ( Decreto 103/2011, de 1 de julio, BOE de 24 de septiembre de 2011 y Decreto 225/2013, de 3 de diciembre; BOE de 27 de febrero de 2015, respectivamente) y de Guadiana del Caudillo por segregación del de Badajoz (Decreto 29/2012, de 17 de febrero; BOE de 3 de agosto de 2012). Es particularmente llamativo el Decreto 23/2018, de 20 de febrero, por el que se constituye el núcleo de población de la Moheda de Gata, perteneciente al municipio de Gata, en entidad local de ámbito territorial inferior al municipio, que también se rige por la legislación anterior a la LRSAL pues el acuerdo de iniciación del expediente de creación de la citada entidad inframunicipal (con un núcleo de población de 600 habitantes) se adoptó en sesión plenaria el 30 de agosto de 2010 y la solicitud del Ayuntamiento de Gata fue presentada el 7 de septiembre de 2010.

20 En concreto se trata de los Decretos del Consejo de Gobierno andaluz 105/2015, de 17 de marzo, por el que se aprueba la creación del municipio de Domingo Pérez de Granada por segregación del término municipal de Iznalloz (Granada) (BOE de 7 de marzo de 2016); 62/2015, de 3 de febrero, por el que se aprueba la creación del municipio de Játar por segregación del término municipal de Arenas del Rey (Granada) (BOE 15 de diciembre de 2015); 144/2015, de 2 de junio, por el que se aprueba la creación del municipio de Balanegra por segregación del término municipal de Berja (Almería) (BOE 22 de septiembre de 2015); 135/2014, de 30 de septiembre, por el que se aprueba la segregación de la entidad local autónoma de Montecorto, del término municipal de Ronda (Málaga), para su constitución como nuevo municipio (BOE de 5 de mayo de 2015); 140/2014, de 7 de octubre, por el que se aprueba la creación del municipio de Dehesas Viejas por segregación del término municipal de Iznalloz (Granada) (BOE 5 de mayo de 2015); y 167/2014, de 2 de diciembre, por el que se aprueba la creación del municipio de Serrato por segregación del término municipal de Ronda (Málaga) (BOE 5 de mayo de 2015).

Distinto es el supuesto del Decreto Foral 27/2016, de 20 de diciembre, que aprueba la segregación de ltsaso del municipio Ezkio-ltsaso y su constitución en municipio independiente, pues el límite de los 5.000 habitantes no resulta de aplicación según establece el artículo 1.5 de la de la Norma Foral 13/2014, de 17 de noviembre, sobre la singularidad foral en la aplicación de las medidas de racionalización y sostenibilidad de la Administración Local en el Territorio Histórico de Gipuzkoa con apoyo en la Disposición adicional primera de la LRSAL.

${ }^{21}$ La creación de nuevos municipios en la Ley 7/1993, de 22 de julio, de Demarcación exigía, entre otros requisitos, un núcleo con una población no inferior a 4.000 habitantes y separado del municipio matriz con una franja de terreno clasificada como suelo no urbanizable de una anchura mínima de 7.500 metros, pero estos requisitos se rebajaban a 2.500 habitantes y una franja de suelo no urbanizable de 5.000 metros si el núcleo de población que aspiraba a segregarse se había constituido en entidad local autónoma. La Ley 5/2010, de 11 de junio, de Autonomía Local de Andalucía, que deroga la Ley 7/1993, ha suprimido tales exigencias. Puede verse M. REBOLLO PUIG y E. CARBONELL PORRAS, "La Administración local en la legislación andaluza”, en Tratado de Derecho Municipal, 2003, Tomo II, págs. 2.008-2.842; y E. CARBONELL PORRAS, "La Administración local en el Estatuto de Autonomía de 2007 y en la reciente legislación andaluza", en Tratado de Derecho Municipal, 2011, Tomo IV, págs. 4.521-4.564. También M. REBOLLO PUIG y R. PIZARRO NEVADO, "Las Entidades Locales Autónomas", en Revista Andaluza de Administración Pública, núm. 42, 2001, pág. 59 y ss. 
REALA. Nueva Época - N. 9 9, Abril 2018 - ISSN: 1989-8975 - DOI: 10.24965/reala.v0i9.10513 - [Págs. 5-21]

La alteración de términos municipales en la reforma local de 2013: crónica de un fracaso anunciado

Eloísa Carbonell Porras

los nuevos requisitos del artículo 13. 2 LBRL a los procedimientos iniciados antes de la entrada en vigor de la LRSAL, posición defendida por la Comunidad Autónoma y apoyada por el Consejo Consultivo de Andalucía ${ }^{22}$.

\section{LA FUSIÓN VOLUNTARIA DE MUNICIPIOS}

\section{a) Generalidades}

Desde la redacción originaria, el artículo 13. 3 LBRL se refería a una posible acción estatal de fomento de la fusión de los municipios, sin perjuicio de las competencias de las Comunidades Autónomas. El Tribunal Constitucional, como es sabido, ha entendido que esta habilitación al Estado no restringe las competencias de las Comunidades Autónomas en orden a las alteraciones de términos municipales, que se rigen por la legislación autonómica sin más límites que las previsiones procedimentales y sustantivas del propio artículo 13, e incluso ha subrayado que «ese fomento estatal, si en verdad aspira a ser efectivo, no será impensable, sino todo lo contrario, que se dirija a las propias Comunidades Autónomas, que retienen la competencia plena y efectiva para materializar esas alteraciones territoriales» ${ }^{23}$. Aunque el respeto por estas competencias autonómicas no está tan claro como se verá, lo cierto es que la reforma parece confiar en que la nueva regulación de la fusión de municipios contribuirá a corregir la planta municipal ${ }^{24}$. A tal finalidad, con un orden y redacción discutible, la LRSAL incorpora los nuevos apartados 4, 5 y 6: el primero, sumamente largo y complejo, se refiere al convenio de fusión, fijando sus consecuencias y las acciones de fomento; el apartado 5 , alude a la participación de las Diputaciones provinciales; y, en el apartado 6 , se trata de la aprobación del convenio de fusión. Por otra parte, la posible fusión de municipios es una de las medidas que los municipios que incumplen los principios de sostenibilidad financiera y estabilidad presupuestaria pueden adoptar en aplicación del artículo 116 bis LBRL en los términos que veremos. Seguidamente se intentan sistematizar los principales aspectos de la fusión de municipios en la LBRL.

En todo caso, debe tenerse presente que cualquier medida tendente a suprimir municipios suele contar con la oposición de los vecinos y genera no pocos $\operatorname{conflictos}^{25}$. Al respecto puede traerse a colación la fusión

Sobre esta cuestión después de la LRSAL, véase M. PONS-PORTELLA, “La población...”, cit. y L. M. ARROYO YANES, "Incidencia...", cit., pág. 923 y ss.

${ }_{22}$ El Consejo Consultivo, en su dictamen 98/2014, de 18 de febrero, que resolvió una consulta facultativa en relación con la aplicación de la Ley 7/1993 (derogada en 2010 pero aplicable al procedimiento que motivó la consulta), entendió que los requisitos para la creación de un nuevo municipio que había introducido la LRSAL en el artículo 13. 2 LBRL eran de aplicación inmediata al tratarse de una disposición de derecho material para la que no se había previsto régimen transitorio alguno. Después y respecto de un concreto Proyecto de decreto de creación de un nuevo municipio por segregación (el de Montecorto) vuelve a formularse la misma cuestión, que el Consejo Consultivo, en el dictamen 609/2014, de 24 de septiembre, resuelve en sentido contrario e informa favorablemente aunque el nuevo municipio no cumple el nuevo requisito de población de la legislación estatal básica. A pesar de que el Consejo Consultivo entiende que no existen derechos adquiridos ni se trataría de una aplicación retroactiva de la LRSAL considera razonable el informe de la Dirección General de Administración Local de la Consejería, avalado por el Ministerio de Hacienda y Administraciones Públicas al que se elevó consulta, que defiende que el nuevo artículo 13, 2 LBRL no es de aplicación a los procedimientos de creación de municipios mediante la segregación de núcleos poblacionales de sus respectivos términos municipales, iniciados al amparo de la legislación autonómica con anterioridad a la entrada en vigor de la LRSAL. Este dictamen cuenta, no obstante, con un voto particular formulado por dos Consejeros que defienden la inmediata aplicación de los nuevos requisitos a todos los procedimientos que no hubieran finalizado antes de la entrada en vigor de la LRSAL. En los mismos términos se pronuncian los dictámenes del Consejo Consultivo, 37/2014, de 30 de septiembre, 738/2014, de 12 de noviembre, 25/2015, de 21 de enero, 125/2015, de 25 de febrero, 250/2015, de 15 de abril, todos favorables a la creación de los nuevos municipios por segregación, y 299/2015, de 29 de abril, 426/2015, de 17 de junio y 754/2015, de 18 de noviembre, aunque estos tres últimos informan desfavorablemente la creación de los nuevos municipios de Fuente Carreteros por segregación de Fuente Palmera (Córdoba), de La Guijarrosa por segregación de Santaella (Córdoba) y de San Martín del Tesorillo, por segregación de Jimena de la Frontera (Cádiz) al considerar que existen dudas sobre la viabilidad económica y la suficiencia financiera de los nuevos municipios.

${ }_{23}$ SSTC 214/1989, de 21 de diciembre, relativa a la LBRL y 103/2013, de 25 de abril, sobre la Ley 57/2003, de 16 de diciembre, de medidas para la modernización del Gobierno Local.

${ }^{24}$ El Preámbulo de la LRSAL subraya que «por primera vez se introducen medidas concretas para fomentar la fusión voluntaria de municipios de forma que se potencie a los municipios que se fusionan ya que contribuyen a racionalizar sus estructuras y superar la atomización del mapa municipal. Entre estas medidas de incentivo se encuentran el incremento de su financiación, la preferencia en la asignación de planes de cooperación local o de subvenciones, o la dispensa en la prestación de nuevos servicios obligatorios como consecuencia del aumento poblacional. Además, si se acordara entre los municipios fusionados alguno de ellos podría funcionar como forma de organización desconcentrada, lo que permitiría conservar la identidad territorial y denominación de los municipios fusionados aunque pierdan su personalidad jurídica. Por último, estas medidas de fusiones municipales incentivadas, que encuentran respaldo en la más reciente jurisprudencia constitucional, STC 103/2013, de 25 de abril, supondrán, en definitiva, que los municipios fusionados percibirán un aumento de la financiación en la medida en que los municipios de menor población recibirán menos financiación».

${ }^{25}$ L. COSCULLUELA MONTANER, "Presentación”, en Crisis económica y reforma del régimen local, 2012, pág. 17, se refiere a las razones sentimentales, políticas y a la consideración del municipio como una entidad natural que dificultan cualquier reforma del mapa municipal. 
voluntaria anterior a la LRSAL entre los municipios de Oza dos Ríos y Cesuras para la constitución del Municipio de Oza-Cesuras en la Comunidad Autónoma de Galicia, acordada por Decreto 83/2013, de 6 de junio, que ha ocasionado diversos procesos judiciales relacionados con la mayoría exigida para la aprobación en los plenos municipales ${ }^{26}$. También en esta Comunidad Autónoma se ha producido la que, salvo error, es la única fusión voluntaria de municipios aprobada después de la entrada en vigor de la reforma de 2013 , la de los Municipios Cerdedo y Cotobade para la constitución del Municipio de Cerdedo-Cotobade aprobada por Decreto 134/2016, de 22 de septiembre ${ }^{27}$. Esta fusión puede aportar algo de luz en la resolución de las cuestiones de interés que la nueva regulación estatal básica suscita.

\section{b) Municipios susceptibles de fusionarse}

El artículo 13. 4 LBRL se refiere a la fusión de «municipios colindantes dentro de la misma provincia, con independencia de su población». El legislador estatal básico no ha querido fijar más condicionantes a los municipios fusionados, que no podrán segregarse hasta transcurridos diez años desde la adopción del convenio de fusión (y en tal caso deberán ajustarse a las nuevas reglas básicas que rigen la creación de nuevos municipios). La fusión de municipios determinará la creación de un nuevo municipio, pero es un supuesto distinto al de la segregación de un núcleo de población para constituir un nuevo municipio antes analizada y, por tanto, no son exigibles los mismos requisitos ${ }^{28}$. En, consecuencia, podrían acogerse a este régimen todos los municipios con independencia de su población. No obstante, como después se verá, las ventajas en la financiación del nuevo municipio se refieren a los municipios que no son capitales de provincia o de Comunidad Autónoma ni tienen una población de derecho igual o superior a los 75.000 habitantes. Por lo tanto, el legislador está pensando en los municipios más pequeños, aunque en teoría también podrían celebrar un convenio de fusión municipios con mayor población aunque obtendrían escasas ventajas. Por eso parece claro que no se tienen presentes otros problemas que suscita nuestra planta municipal como, por ejemplo, los supuestos en los que los que se confunden los núcleos de población de varios municipios como consecuencia del desarrollo urbanístico.

\section{c) Naturaleza del convenio de fusión y su relación con el procedimiento general para alterar los términos municipales}

Los municipios «podrán acordar su fusión mediante un convenio de fusión, sin perjuicio del procedimiento previsto en la normativa autonómica» según dispone el artículo 13. 4 LBRL. El primer interrogante surge del sentido de este último inciso, cuestionándose la relación entre este convenio de fusión y la legislación autonómica, que es la competente para regular la alteración de los términos municipales (y la fusión de municipios lo es), sin más condicionantes que los previstos en el propio artículo 13 LBRL. Parece claro

26 En un primer momento se recurrieron los acuerdos del Concello de Cesuras, de 11 de enero y 22 de febrero de 2013 , si bien el recurso se inadmitió por tratarse de actos de trámite del procedimiento de fusión no susceptibles de impugnación autónomas (Vid. STSJ de Galicia 653/2014, de 10 julio, que confirma en recurso de apelación núm. 4243/2014 el auto del Juzgado de lo Contenciosoadministrativo núm. 1 de A Coruña). Posteriormente, se recurre el Decreto 83/2013 (publicado en el BOE de 18 de junio 2013 ), y el Tribunal Superior de Justicia de Galicia plantea la cuestión de inconstitucionalidad en relación con el art. 32.1 de la Ley 5/1997, de 22 de julio, de Administración local de Galicia, que exigía «el voto favorable de las dos terceras partes del número de hecho y, en todo caso, de la mayoría absoluta del número legal de miembros de la corporación» para los acuerdos de alteración de términos municipales con carácter voluntario, si bien esta mayoría cualificada entraba en contradicción con la mayoría absoluta del régimen legal de miembros del artículo 47.2 a) LBRL, que había sido modificado por la Ley 57/2003, de 16 de diciembre, de medidas para la modernización del gobierno local, que había sido la seguida en los acuerdos municipales de fusión. El Tribunal Constitucional, en sus sentencia $102 / 2016$, de 25 de mayo, y 116/2016, de 20 de junio inadmite la cuestión. Resulta de interés, no obstante, la invocación por el Tribunal Constitucional de la cláusula de prevalencia del artículo 149. 3 de la Constitución, que provoca la inaplicación de la norma autonómica que deviene contraria a una norma estatal básica posterior. En consecuencia, las sentencias del Tribunal Superior de Justicia de Galicia 583 , 596 y 588, de 6 octubre de 2016 rechazarán la pretendida nulidad del Decreto 83/2013. Puede verse A. R. ANTELO MARTíNEZ, "Fusiones de municipios: ¿prevalencia del derecho estatal en el régimen de adopción de acuerdos? Especial referencia al caso de los municipios de Ozas y Cesuras en la provincia de A Coruña”, en Revista de Estudios Locales. Cunal, núm. 155, 2013, págs. 91-102 y A. DE DIEGO GÓMEZ, "La fusión de Ayuntamientos con especial referencia a Galicia", en Revista Gallega de Administración Pública núm. $47,2014$.

27 BOE de 27 de enero de 2017.

28 Algunos autores han deducido de la nueva regulación que el municipio resultante deberá alcanzar los 5.000 habitantes que se exige para crear un nuevo municipio, excluyéndose los más necesitados de fusionarse. Vid. L. M. ARROYO YANES, "Incidencia..., " cit., pág. 954 y M. a A. ARIAS MARTíNEZ, "La fusión...", cit., págs. 124-125. En contra, M. ALMEIDA CERREDA, "Un nuevo instrumento...", cit., pág. 342, señala que contradice el tenor literal del artículo 13.4, que expresamente dice que los ayuntamientos se pueden fusionar «independientemente de su población», y, en segundo lugar, porque tal interpretación es contraria al espíritu de la LRSAL, que es el de promover fusiones, en números absolutos. 
que las medidas coactivas de corrección de la planta local previstas en la legislación de las Comunidades Autónomas no resultan afectadas por la nueva regulación de la fusión ${ }^{29}$. Incluso son admisibles, en su caso, fusiones no coactivas al margen de esta nueva regulación como se deduce de la literalidad del precepto: «podrán acordar su fusión». El problema fundamental se plantea cuando se opte por este convenio de fusión, cuestionándose su relación con el procedimiento previsto en la legislación autonómica, es decir, si el convenio constituye una alternativa a los procedimientos de fusión previstos en la normativa autonómica o, por el contrario, un trámite que se insertaría en dichos procedimientos. Para unos, el legislador estatal ha regulado un procedimiento y un régimen paralelo a los procedimientos de fusión previstos en la legislación autonómica y, en consecuencia, se invaden las competencias de las Comunidades Autónomas para la alteración de los términos municipales ${ }^{30}$; para otros, la invasión competencial que en tal caso se produciría se salvaría con la aprobación del convenio por quién disponga la legislación autonómica para la fusión de municipios ${ }^{31}$; e incluso se ha propuesto la necesidad de regular un procedimiento simplificado para que las Comunidades Autónomas aprueben el convenio de fusión ${ }^{32}$. El Fundamento Jurídico $6 .^{\circ}$ de la STC 41/2016 afronta esta cuestión en términos oscuros: por un lado, se subraya que «la nueva redacción del art. 13 LBRL sigue confiando el régimen de creación, supresión y alteración de los términos municipales a la legislación de las comunidades autónomas sobre régimen local» o que «la Comunidad Autónoma no ha quedado al margen del proceso de fusión voluntaria. El apartado 1 del art. 13, además de prever el dictamen preceptivo del órgano consultivo superior de la Comunidad Autónoma y el informe de la Administración que tenga atribuida la tutela financiera del ente local, remite el régimen de la fusión de municipios a la legislación autonómica. El apartado 3 deja a salvo la competencia autonómica en materia de incentivos a la fusión; el apartado 4 señala que los municipios adoptan el convenio de fusión, sin perjuicio del procedimiento previsto en la normativa autonómica; el apartado 5 atribuye a las Comunidades Autónomas la colaboración con las Diputaciones provinciales o entes equivalentes en la supervisión y la coordinación de los servicios resultantes de la fusión». Pero, por otro lado, se indica que «los órganos representativos de los Ayuntamientos afectados son quienes adoptan el convenio de fusión, sin perjuicio del procedimiento previsto en la normativa autonómica» o que "el legislador estatal, en el ejercicio de la competencia que le reconoce el artículo 149.1.18. ${ }^{\circ}$ de la Constitución, ha optado aquí, como en otros supuestos, por ampliar el alcance y contenido de la autonomía municipal, sin que a ello pueda imputarse exceso competencial de ningún tipo», e incluso se invoca la STC 214/1989, que respaldo la supresión de la intervención autonómica en la aprobación de los Estatutos de las Mancomunidades ${ }^{33}$. Parece, por

29 Así lo ha reconocido la STC 41/2016: el nuevo artículo 13 LBRL «no impide que la Comunidad Autónoma desarrolle una política propia sobre fusión de los municipios situados en su ámbito territorial ni, en general, que intervenga de diferentes modos sobre el mapa municipal... Nada dice, en particular, sobre las fusiones imperativas... La legislación básica sigue optando en este punto por no establecer las directrices fundamentales de un plan general de reestructuración del mapa municipal español. Por tanto, "la legislación de las Comunidades Autónomas sobre régimen local" podrá regular, planificar y acordar estas fusiones imperativas con los escasos límites que resultan del primer apartado del art. 13 LBRL».

30 J. M. DÍAZ LEMA, “La proyección...”, cit., pág. 127-128, el legislador estatal ha pretendido crear un procedimiento y una figura paralela a las fusiones previstas en la legislación autonómica que naturalmente se mantendría («sin perjuicio de...») y, en consecuencia ha invadido las competencias autonómicas en la materia. También J. AMENÓS ÁLAMO, "El elemento...”, pág. 60, entiende que el convenio de fusión no requiere la ratificación posterior por la Comunidad Autónoma o la Diputación provincial.

31 Vid. M. J. ALONSO MÁS, “EI nuevo régimen...”, cit., pág. 314.

32 Vid. M. ALMEIDA CERREDA, "La planta local...", cit., pág. 16.

33 La STC 41/2016 dispone: «Al desestimar la impugnación dirigida contra la redacción originaria del art. 13 LBRL, la STC 214/1989 declaró que al órgano autonómico competente corresponderá decretar [las alteraciones de términos municipales], de acuerdo con la regulación propia de la Comunidad que solo se encuentra limitada por las previsiones de orden procedimental y sustantivo que, respectivamente, prevén los párrafos $1 .^{\circ}$ y $2 .^{\circ}$ del mismo art. 13 (FJ. ${ }^{\circ}$ 9). Para calibrar adecuadamente el alcance de esta declaración en el contexto del presente proceso, es preciso tener en cuenta que la Sentencia describía la regulación entonces controvertida, que nada disponía en torno a quién formaliza en concreto el acuerdo de fusión voluntaria. Admitía que cada Comunidad Autónoma regulase este aspecto y, por tanto, que se atribuyese la decisión final con grados variables de discrecionalidad y, en última instancia, que la Administración autonómica pudiese oponer resistencia a la voluntad de fusión de los municipios de su ámbito territorial. El art. 13 LBRL contiene ahora otra regulación conforme a la que los órganos representativos de los Ayuntamientos afectados son quienes adoptan el convenio de fusión, sin perjuicio del procedimiento previsto en la normativa autonómica. A su vez, esa misma Sentencia resolvió una impugnación sobre el régimen jurídico de las mancomunidades muy similar a la aquí planteada. La Junta de Galicia razonaba entonces que la LBRL invadía las competencias autonómicas por entregar a los municipios el poder decisorio en lo concerniente tanto a la creación de las mancomunidades, como a la elaboración de sus estatutos. La STC 214/1989 desestimó la impugnación. Además de destacar la remisión contenida en el art. 44.3 LBRL a favor de la legislación autonómica, declaró: El legislador estatal, en el ejercicio de la competencia que le reconoce el art. 149.1.18. ${ }^{\text {a }}$ de la Constitución, ha optado aquí, como en otros supuestos, por ampliar el alcance y contenido de la autonomía municipal, sin que a ello pueda imputarse exceso competencial de ningún tipo, al ser simple concreción de una legítima opción política que, cualquiera que sea la valoración que pueda suscitar, constitucionalmente no permite juicio alguno de este Tribunal (FJ 14). Según hemos declarado recientemente, la concepción que desarrolla la STC 214/1989 parte de que las mancomunidades, en la medida en que no son 
tanto, que el acuerdo de fusión voluntaria de los municipios sería suficiente para que se produjera la misma pero, además, habría que respetar los procedimientos previstos en la legislación autonómica. Para integrar ambos planteamientos habría que entender que el convenio de fusión por los municipios vincularía al órgano competente de la Comunidad Autónoma (o al que la legislación haya atribuido la competencia) que se limitaría a ratificarlo, sin perjuicio de incorporar en la resolución que acuerde la fusión otros posibles contenidos que exija la legislación autonómica y de la tramitación del procedimiento previsto en la misma. Las Comunidades Autónomas podrán adaptar, en su caso, sus regulaciones para facilitar la alteración de los términos municipales en estos casos de fusión voluntaria y completar las previsiones del convenio de fusión.

Desde este planteamiento, el convenio de fusión voluntaria de municipios es «un acuerdo con efectos jurídicos» en el amplio sentido del artículo 47 de la Ley 40/2015, de 1 de octubre de Régimen Jurídico del Sector Público que se rige por lo previsto en el artículo 13 LBRL y la legislación autonómica que pueda dictarse en su desarrollo ${ }^{34}$. Puede considerarse un acuerdo de los previstos en el artículo 86 de la Ley 39/2015, de 1 de octubre, de Procedimiento Administrativo Común, sobre la terminación convencional, que se insertaría en el procedimiento para la alteración de términos municipales regulado en la legislación autonómica. De esta forma, se respetaría la normativa de cada Comunidad Autónoma que, no olvidemos, es la competente en relación con la alteración de términos municipales y la fusión lo es. El convenio de fusión deberá ser aprobado por mayoría simple de cada uno de los plenos de los municipios fusionados según dispone el artículo 13.6 LBRL. No obstante, este apartado añade: «la adopción de los acuerdos previstos en el artículo 47. 2, siempre que traigan causa de una fusión, será por mayoría simple de los miembros de la corporación». La interpretación de este inciso plantea alguna duda pues, como es sabido, el artículo 47. 2 LBRL relaciona los acuerdos que deben adoptarse por mayoría absoluta entre los que se incluye en primer lugar «la creación y supresión de municipios y la alteración de términos municipales». Parece que el legislador estatal básico ha rebajado la mayoría exigible a todos los supuestos de fusión de municipios, y no sólo a los que deriven del convenio de fusión voluntaria del artículo 13 LBRL. Si eso era lo pretendido debió modificar expresamente el artículo 47. 2 LBRL excepcionando la mayoría absoluta cuando se trate de fusionar municipios. En todo caso el Tribunal Constitucional (STC 41/2016) ha amparado esta mayoría en la competencia estatal del artículo 149. 1. 18. ${ }^{\circ}$ de la Constitución, señalando que «más allá de la virtualidad real de esta previsión (y de la valoración de oportunidad que merezca que una decisión evidentemente trascendental para la vida municipal no esté sujeta a un régimen de mayoría cualificada), es claro que dinamiza el principio constitucional de autonomía local (art. $137 \mathrm{CE}$ ) y facilita las fusiones voluntarias con el fin de lograr una reducción del mapa municipal instrumental de los principios de eficacia de la actuación administrativa (art. 103.1 CE), eficiencia en el uso de los recursos públicos (art. 31.2 CE) y estabilidad presupuestaria (art. $135 \mathrm{CE}$ )». Sin perjuicio de lo anterior, comparto las críticas generalizadas a esta regla ${ }^{35}$. No resulta congruente que se requiera mayoría absoluta de los plenos municipales para mancomunarse, aprobar su reglamento orgánico o alterar la calificación jurídica de sus bienes, entre otros asuntos, y sea suficiente la mayoría simple para desaparecer como municipio.

En relación con el engarce del convenio de fusión voluntaria y su regulación en la $L B R L$ con la regulación de la alteración de términos municipales prevista en la legislación autonómica es ilustrativo el procedimiento

titulares de otros intereses que los de los municipios encomendantes, participan de la autonomía que constitucionalmente se predica de los entes locales que las forman-. Por eso, solo podría concluirse que la regulación estatal impugnada excede del ámbito material de lo básico, si no fuera necesaria para garantizar la autonomía de los municipios mancomunados (STC 103/2013, FJ 3)».

34 Sobre la nueva regulación de los convenios puede verse, entre otros, H. GOSÁLBEZ PEQUEÑO, "Los convenios administrativos", en Innovaciones en el procedimiento administrativo común y el régimen jurídico del sector público, 2016, pág. 265 y ss.; R. BUSTILLO BOLADO, "Los convenios", en Tratado de procedimiento administrativo común y régimen jurídico básico del sector público, tomo I, pág. 1.057 y ss.; M. HERNANDO RYDINGS, "La colaboración interadministrativa local: novedades en el nuevo régimen jurídico de los convenios y de los consorcios", en El nuevo procedimiento administrativo local tras la Ley 39/2015, 2016, pág. 736 y ss. y R. PIZARRO NEVADO, "Disposiciones generales, principios de actuación y funcionamiento del sector público", en El nuevo régimen jurídico del sector público, 2016, pág. 137 y ss., y "Significación y claves de la Ley de Régimen Jurídico del Sector Público", en Revista Gallega de Administración Pública núm. 53, 2017, pág. 327 y ss.

Para J. M. DÍAZ LEMA, “La proyección...”, cit., págs. 126-127 «los convenios de fusión son instrumentos contractuales entre dos o más municipios, de carácter temporal, en virtud de los cuales se integran los territorios, poblaciones y organizaciones correspondientes, que el legislador estatal inventiva a través de mejoras en la financiación de los mismos y otras medidas», se rigen por el régimen general de los convenios interadministrativos de los artículos 6 y 9 de la Ley 30/1992 y 56 LBRL y «representan una forma organizativa informal o atípica, al alcance de cualesquiera administraciones; en este sentido no vienes a ser más que una forma de mancomunidad municipal, bien que con carácter general en la medida en que afecta al conjunto de la actividad municipal y por supuesto a la organización entera».

35 Vid. J. AMENÓS ÁLAMO, “El elemento...", cit., pág. 60, que señala la ironía de que resulta más sencillo fusionarse que crear o modificar una mancomunidad. También M. a A. ARIAS MARTíNEZ, "La fusión..., cit., págs. 122 y 125; o M. ALMEIDA CERREDA, "La planta local...", cit., pág. 19. 
de fusión seguido por los municipios de Cerdedo y Cotobade para la constitución del nuevo municipio de Cerdedo-Cotobade al que se hizo antes referencia, pues toma en consideración la nueva regulación básica, pero también la Ley 5/1997, de 22 de julio, de Administración local de Galicia, integrando ambas normas y, en lo que interesa particularmente, aprobándose la fusión por la Comunidad Autónoma ${ }^{36}$.

\section{d) Consecuencias de la fusión}

El legislador estatal básico también regula con cierto detalle las consecuencias organizativas, presupuestarias, y demás circunstancias derivadas de la fusión. Concretamente la fusión supondrá:

- La integración de los territorios, poblaciones y organizaciones de los municipios, incluyendo los medios personales, materiales y económicos, del municipio fusionado. Los Plenos aprobarán las medidas que adecuen las estructuras organizativas, inmobiliarias, de personal y de recursos, si bien su ejecución no podrá suponer incremento alguno de la masa salarial en los municipios afectados.

- El órgano del gobierno del nuevo municipio estará constituido transitoriamente por la suma de los concejales de los municipios fusionados en los términos previstos en la Ley Orgánica 5/1985, de 19 de junio, del Régimen Electoral General. Con esta solución el legislador estatal básico garantizaría el mantenimiento en el cargo de todos los concejales de los municipios fusionados hasta la celebración de las siguientes elecciones municipales, momento en el que desaparecerá la situación transitoria debiendo constituirse la Corporación con el número de concejales que le correspondan según su población.

- El convenio de fusión podrá acordar que cada uno de los municipios fusionados, o alguno de ellos funcione como la nueva forma de organización desconcentrada que regula el artículo 24 bis LBRL. Este artículo se refiere a los nuevos «entes de ámbito territorial inferior al municipio, que carecerán de personalidad jurídica, como forma de gestión desconcentrada», que la reforma local ha introducido como consecuencia de la supresión de las Entidades locales inframunicipales. Hasta la reforma de 2013 una de las soluciones que la legislación ofrecía a los núcleos de población diferenciada que perdieran su condición de municipio por su agregación o incorporación a otro colindante era constituirse en Entidades de ámbito territorial inferior al municipio ${ }^{37}$. No parece que la creación de ese «ente»/ órgano de gestión desconcentrada suponga realmente ningún estímulo para la fusión del municipio ${ }^{38}$.

- El nuevo municipio se subrogará en todos los derechos y obligaciones de los anteriores municipios. No obstante, si uno de los municipios fusionados estuviera en situación de déficit se podrán integrar, por acuerdo de los municipios fusionados, las obligaciones, bienes y derechos patrimoniales que se consideren liquidables en un fondo, sin personalidad jurídica y con contabilidad separada, adscrito al nuevo municipio, que designará un liquidador al que le corresponderá la liquidación de este fondo. Esta liquidación deberá llevarse a cabo durante los cinco años siguientes desde la adopción del convenio de fusión, sin perjuicio de los posibles derechos que puedan corresponder a los acreedores. La aprobación de las normas a las que tendrá que ajustarse la contabilidad del fondo corresponderá al Ministro de Hacienda y Administraciones Públicas, a propuesta de la Intervención General de la Administración del Estado. Esta regla está relacionada con el artículo 116. bis. 2. f) LBRL, pues una de las medidas que pueden incluir las Entidades locales que formulen un plan económico financiero por el incumplimiento del objetivo de estabilidad presupuestaria, del objetivo de

36 El procedimiento se inicia con sendos acuerdos municipales de 3 de marzo de 2016, y el sometimiento a información pública según dispone el artículo 32. 2 de la Ley Gallega por un plazo de treinta días desde la publicación en el Diario Oficial de Galicia (realizada los días 16 y 18 de marzo de 2016). El 7 de julio se aprueba el convenio de fusión voluntaria y se produce la aprobación del acuerdo de fusión. Los acuerdos municipales han sido adoptados por mayoría simple en aplicación de la nueva regla básica. Según indica el Decreto 134/2016 se ha evacuado el informe de sostenibilidad financiera, el de la Comisión Gallega de Delimitación Territorial y del Consejo Consultivo, aprobándose la fusión previa deliberación del Consello de la Xunta de Galicia. El Decreto tiene el contenido que exige el artículo 38 de la Ley Gallega, si bien la comisión gestora está integrada por iodos los Concejales en aplicación de la LBRL (y no por los vocales designados por la Consellería en número igual al que corresponda a la nueva población que es lo previsto en el artículo 39 de la Ley Gallega).

37 El artículo 41 del Real Decreto 1690/1986, de 11 de julio, por el que se aprueba el Reglamento de Población y Demarcación Territorial de las Entidades Locales, y, en términos similares, las legislaciones autonómicas contemplaban la posibilidad que los municipios suprimidos por su integración o fusión con otros podrían constituirse en Entidades de ámbito territorial inferior al municipio. Se permitía así, como señala M. REBOLLO PUIG ("La supresión de los pequeños municipios: régimen, alternativas, ventajas e inconvenientes", en Revista de estudios de la administración local y autonómica, núm. 308, 2008, págs. 168 y ss.), que conservarán cierto grado de administración de sus propios asuntos como entidades descentralizadas.

38 Así lo ha señalado R. PIZARRO NEVADO, "Entidades...”, cit., pág. 70. 
deuda pública o de la regla de gasto es una propuesta de fusión con un municipio colindante de la misma provincia. En tal caso, se trataría de impedir que el municipio resultante de la fusión se vea lastrado financieramente desde su constitución ${ }^{39}$.

- El nuevo municipio aprobará un nuevo presupuesto para el ejercicio presupuestario siguiente a la adopción del convenio de fusión.

Por otra parte, el artículo 13. 5 LBRL establece que las Diputaciones Provinciales o entidades equivalente, en colaboración con la Comunidad Autónoma, «coordinarán y supervisarán la integración de los servicios resultantes del proceso de fusión» y asumirán también el seguimiento de la fusión de Entidades Locales que se hubiera acordado en el plan económico-financiero (art. 116. bis. 3 LBRL).

\section{d) Las medidas de fomento de la fusión}

El municipio resultante de la fusión obtendría ciertas ventajas que pueden sistematizarse en las siguientes:

En primer lugar, el artículo 13. 4 LBRL prevé unas reglas de financiación que pretenden estimular la fusión, sobre la base del régimen previsto en el Texto Refundido de la Ley de Haciendas Locales, aprobado por Real Decreto Legislativo 2/2004, de 5 de marzo (en adelante, TRLHL) para los municipios que no son capitales de provincia o de Comunidad Autónoma ni tienen una población de derecho igual o superior a los 75.000 habitantes, y su participación en los tributos del Estado regulada en el artículo 12440: se incrementa en un

39 En este sentido, A. CORCUERA TORRES, "Aspectos financieros de la reforma local”, en Revista de estudios de la Administración Local y Autonómica núm. Extraordinario, 2015 pone de manifiesto las siguientes dificultades de la solución arbitrada por el legislador:

«- Problemas de interpretación de la norma para calcular la situación de déficit. Se plantea la duda de si el cálculo de este término, ajeno a la normativa presupuestaria general, ha de efectuarse en términos de contabilidad nacional, esto es, según el Sistema Europeo de Cuentas o ateniéndose a las normas de contabilidad presupuestaria.

- Problemas de integración de este tipo de fondos en el presupuesto general del municipio, pues la regulación subjetiva del mismo (artículo 164.1 del TRLRHL) no lo contempla, estando regulados únicamente a nivel estatal (artículo 2.2 de la Ley General Presupuestaria). De hecho, su aprobación al margen del presupuesto general podría ser contrario a los principios de unidad y universalidad presupuestaria.

- Problemas a la hora de identificar las obligaciones, bienes y derechos patrimoniales que tienen que separarse por ser los causantes del déficit. En este sentido, sólo una adecuada contabilidad de costes, de la que hoy día carecen los municipios, permitiría conocer fielmente tal parte del patrimonio a segregar.

- La propia figura del liquidador que recuerda al administrador de los procesos concursales, de los que son ajenos los entes públicos.

- Y por último, la necesidad de financiar el fondo para su liquidación, en especial para atender las deudas pendientes con acreedores que, lógicamente, recaerá en el nuevo municipio fusionado».

40 El artículo 124 del TRLHL es del siguiente tenor:

«1. La participación total determinada con arreglo a lo dispuesto en el anterior artículo se distribuirá entre los municipios incluidos en este modelo de financiación con arreglo a los siguientes criterios:

a) El 75 por 100 en función del número de habitantes de derecho de cada municipio, según las cifras de población aprobadas por el Gobierno, que figuren en el último Padrón municipal vigente, ponderadas por los siguientes coeficientes multiplicadores:

\begin{tabular}{llr}
\hline Estrato & Número de habitantes & Coeficientes \\
\hline 1 & De más de 50.000 & 1,40 \\
\hline 2 & De 20.001 a 50.000 & 1,30 \\
\hline 3 & De 5.001 a 20.000 & 1,17 \\
\hline 4 & Hasta 5.000 & 1,00 \\
\hline
\end{tabular}

b) El 12,5 por 100 en función del esfuerzo fiscal medio de cada municipio obtenido en el segundo ejercicio anterior al de la Ley de Presupuestos Generales del Estado correspondiente, ponderado por el número de habitantes de derecho.

A estos efectos, se entenderá por esfuerzo fiscal medio de cada municipio el que para cada ejercicio determinen las Leyes de Presupuestos Generales del Estado en función de la aplicación que por los municipios se haga de los tributos contenidos en esta Ley.

c) El 12,5 por 100 en función del inverso de la capacidad tributaria en los términos que establezcan las Leyes de Presupuestos Generales del Estado.

2. En ningún caso, la financiación de ningún municipio, determinada con arreglo a lo dispuesto en esta sección, podrá ser inferior a la que resulte, en términos brutos, de la liquidación definitiva de la participación en los tributos del Estado del año 2003, entendiéndose ésta en los mismos términos recogidos en el último apartado del artículo precedente. De la aplicación de esta regla no se podrá derivar, para cada ejercicio, un importe total superior al que resulte de lo dispuesto en el artículo 123 de esta Ley». 
0.10\% el coeficiente de ponderación; el esfuerzo fiscal y el inverso de la capacidad tributaria que le corresponda en ningún caso podrá ser inferior al más elevado de los valores previos que tuvieran cada municipio por separado antes de la fusión; y su financiación mínima será la suma de las financiaciones mínimas que tuviera cada municipio por separado antes de la fusión. De la aplicación de estas reglas no podrá derivarse, para cada ejercicio, un importe total superior al que resulte de lo dispuesto en el artículo 123 del TRLHL ${ }^{41}$.

En segundo lugar, «se sumarán los importes de las compensaciones que, por separado, corresponden a los municipios que se fusionen y que se derivan de la reforma del Impuesto sobre Actividades Económicas de la disposición adicional décima de la Ley 51/2002, de 27 de diciembre, de Reforma de la Ley 39/1988, de 28 de diciembre, Reguladora de las Haciendas Locales, actualizadas en los mismos términos que los ingresos tributarios del Estado en cada ejercicio respecto a 2004, así como la compensación adicional, regulada en la disposición adicional segunda de la Ley 22/2005, de 18 de noviembre, actualizada en los mismos términos que los ingresos tributarios del Estado en cada ejercicio respecto a 2006».

En tercer lugar, el municipio resultante de la fusión quedará dispensado de prestar los servicios mínimos de los previstos en el artículo 26 LBRL que le corresponderían por razón de su aumento poblacional. No se establece hasta cuándo se produciría esa dispensa que previsiblemente afectaría a municipios con población inferior a 5.000 habitantes que alcanzarían esa población al fusionarse y, consecuentemente, deberían prestar los servicios de parque público, biblioteca pública y tratamiento de residuos según la letra b) del artículo 26. 1. En todo caso el legislador debió establecer un plazo pues resulta inadmisible que la dispensa se perpetúe en el tiempo ${ }^{42}$. La respuesta ante esta indeterminación del legislador es entender que la dispensa resulta aplicable hasta que se celebren elecciones en el municipio resultante de la fusión, circunstancia que determinará el fin de la transitoriedad organizativa y, consecuentemente, debería comenzar la prestación de los servicios obligatorios en atención a su población. Mientras tanto debería ser la Diputación provincial o entidad equivalente la que asumiera la prestación de esos nuevos servicios en aplicación del artículo 13. 5 LBRL ${ }^{43}$.

En cuarto lugar, se dispone que «durante al menos los cinco primeros años desde la adopción del convenio de fusión, tendrá preferencia en la asignación de planes de cooperación local, subvenciones, convenios y otros instrumentos basados en la concurrencia. Este plazo podrá prorrogarse por la Ley de Presupuestos Generales del Estado». Este inciso ha sido interpretado por el Tribunal Constitucional en su sentencia 41/2016 en los siguientes términos:

«Esta regulación es poco específica, pero puede interpretarse sin dificultad que el indicado criterio de preferencia se aplica a la distribución de ayudas económicas a las que puedan optar los municipios fusionados en régimen de concurrencia con otras entidades, siempre que el Estado haya hecho valer respecto de cada concreto programa o instrumento, bien su competencia básica respecto de la planta local con la finalidad de incentivar las fusiones municipales, bien otros títulos de intervención que le permitan establecer, al menos, las condiciones esenciales del otorgamiento de acuerdo con la doctrina constitucional (STC 150/2012, de 5 de julio, FJ 6 , que parte de la STC 13/1992, FJ 8).

El tenor literal del precepto, aunque impreciso, no da pie a interpretar que el legislador estatal haya pretendido vulnerar la doctrina constitucional condicionando todas las políticas subvencionales de las Comunidades Autónomas relacionadas con los municipios o, más precisamente, extendiendo la aplicación del indicado criterio de preferencia a ayudas cuya regulación corresponde en exclusiva a las Comunidades Autónomas por referirse a materias en que no entra en juego título estatal alguno. Consecuentemente, la medida examinada, en la medida en que se aplica sólo a subvenciones que el Estado puede consignar en sus presupuestos generales y respecto de las que puede regular, al menos, las condiciones esenciales del otorgamiento por disponer de algún título de intervención, no vulnera el sistema constitucional de distribución competencial.»

${ }^{41}$ A. CORCUERA TORRES, "Aspectos...", cit., señala que se establece «una especie de "cortafuegos jurídico" que impide que la cantidad recibida por este sistema de financiación se incremente para el ente fusionado más allá del límite que establece el citado artículo 123, que se refiere a que la participación total para cada ejercicio se determinará aplicando un índice de evolución a la correspondiente al año base, y que refleja el incremento que experimenten los ingresos tributarios del Estado entre el año al que corresponda la participación y el año base». Por eso entiende que no es una medida de fomento de la fusión de municipios, sino de protección del Estado para impedir que se incremente desmesuradamente la participación en sus tributos y propone su revisión.

${ }^{42}$ En el mismo sentido, M. ALMEIDA CERREDA, "La planta...", cit., pág. 133; o A. CORCUERA TORRES, "Aspectos financieros...", cit.

${ }^{43}$ Así lo señala J. AMENÓS ÁLAMO, "El elemento territorial...", cit., pág. 62. 
Por lo tanto, la preferencia a favor de los municipios fusionados tiene un alcance reducido y limitado a las ayudas de cualquier tipo del Estado.

\section{e) La propuesta de fusión del artículo 116. bis LBRL}

La reforma local también prevé la fusión de municipios como una de las medidas posibles en municipios que no cumplan con las exigencias de estabilidad presupuestaria y sostenibilidad financiera. Los municipios que incumplan el objetivo de estabilidad presupuestaria, el de deuda pública o de la regla de gasto, deberán formular su plan económico-financiero de conformidad con el artículo 21 de la Ley Orgánica 2/2012, de 27 de abril, de Estabilidad Presupuestaria y Sostenibilidad Financiera y adicionalmente las medidas del nuevo artículo 116 bis LBRL. Este precepto hace expresa referencia a la propuesta de fusión con un municipio colindante de la misma provincia como una de las medidas que «al menos» debe incluir el plan económicofinanciero ${ }^{44}$. La doctrina ha criticado esta regulación por afectar a la autonomía local y a las competencias autonómicas, entre otras razones ${ }^{45}$. Ciertamente el artículo, como tanto otros de la reforma, es confuso y contradictorio: de la expresión «al menos» se deduce que el plan debería incluir como mínimo todas medidas posibles, incluida la propuesta de fusión. Pero para formular esta propuesta resulta necesario el acuerdo con alguno de los municipios colindantes que tal vez se alcance si alguno de ellos presenta la misma situación económico-financiera, aunque difícilmente un municipio saneado aceptará fusionarse, a pesar de la creación del fondo sin personalidad al que antes se aludió. Quizá por estos problemas, el Tribunal Constitucional ha interpretado el precepto excluyendo la obligatoriedad de esta propuesta de fusión.

En efecto, la STC 41/2016 (a la que remiten las posteriores) rechaza que el artículo 116 bis LBRL, invada la reserva de Ley Orgánica o contradiga sus previsiones y encuadra su regulación en la competencia estatal en materia de hacienda general. Pero, en la STC 180/2016 (que repite la STC 107/2017), también se plantea la posible vulneración de la autonomía local que podría resultar afectada si hubiera que incluir todas las medidas a las que alude el artículo 116 bis. Este planteamiento es rechazado por el Tribunal Constitucional, que destaca que es el Municipio el que elabora el plan económico-financiero e incluirá las medidas que considere precisas para cumplir los objetivos de estabilidad presupuestas y sostenibilidad financiera:

«Cuando el art. 116. bis.2 LBRL dispone que 'el mencionado plan incluirá al menos las siguientes medidas' no ha de entenderse que el ente local está vinculado a recoger en dicho plan todas esas medidas, perdiendo así todo margen de opción en sus decisiones de gasto, sino que debe introducirlas si fueran imprescindibles para recobrar la senda del cumplimiento y en la medida en que lo sean. La cláusula «al menos» significa que el ente local también deberá incluir en el plan otras medidas distintas de las enumeradas en el art. 116 bis.2 LBRL cuando el fin al que se orienta aquél lo exijas».

44 Concretamente el artículo 116. bis. 2 dispone que el plan económico-financiero «incluirá al menos las siguientes medidas»:

a) Supresión de las competencias que ejerza la Entidad Local que sean distintas de las propias y de las ejercidas por delegación.

b) Gestión integrada o coordinada de los servicios obligatorios que presta la Entidad Local para reducir sus costes

c) Incremento de ingresos para financiar los servicios obligatorios que presta la Entidad Local.

d) Racionalización organizativa.

e) Supresión de entidades de ámbito territorial inferior al municipio que, en el ejercicio presupuestario inmediato anterior, incumplan con el objetivo de estabilidad presupuestaria o con el objetivo de deuda pública o que el período medio de pago a proveedores supere en más de treinta días el plazo máximo previsto en la normativa de morosidad.

f) Una propuesta de fusión con un municipio colindante de la misma provincia.

3. La Diputación provincial o entidad equivalente asistirá al resto de corporaciones locales y colaborará con la Administración que ejerza la tutela financiera, según corresponda, en la elaboración y el seguimiento de la aplicación de las medidas contenidas en los planes económicos-financiero. La Diputación o entidad equivalente propondrá y coordinará las medidas recogidas en el apartado anterior cuando tengan carácter supramunicipal, que serán valoradas antes de aprobarse el plan económico-financiero, así como otras medidas supramunicipales distintas que se hubieran previsto, incluido el seguimiento de la fusión de Entidades Locales que se hubiera acordado.»

Como había puesto de manifiesto M. a J. ALONSO MAS, "El nuevo régimen...", cit., pág. 308 el precepto era confuso pues parecía exigir que el plan incluyera todas las medidas, siendo algunas de ellas incompatibles entre sí.

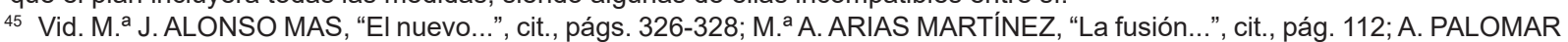
OLMEDA, "La supresión-fusión...”, cit., pág. 244 y ss., que se refiere a este supuesto de fusión como sanción; M. ALMEIDA CERREDA, "La planta local...", cit., pág. 20; A. DE DIEGO GÓMEZ, "Las fusiones...", cit., págs. 556-557; o J. J. DÍEZ SÁNCHEZ, "Estrategias...", cit., pág. 153. 
Con esta interpretación razonable a pesar de la letra del artículo, los Municipios que formulen un plan económico-financiero decidirán si la fusión con un municipio colindante puede suponer la respuesta a sus problemas financieros, sin que estén obligados a ello. Cuando se elija esta opción (si es que se propone en alguna ocasión) la fusión se reconduciría al convenio previsto en el artículo 13 LRBRL que, como se ha visto, regula expresamente la fusión de algún municipio en situación de déficit. Sin perjuicio de lo anterior, y en una muestra más de la precipitada solución a los problemas de la LRSAL, el artículo 116 bis LBRL no contempla la incorporación del municipio, que supone su anexión a uno colindante que podría ser una solución con mayor aplicación práctica. A mi juicio, cabe una interpretación flexible e integradora de ambos preceptos. Un municipio económicamente saneado aceptaría sin dificultades la incorporación de un municipio colindante obligado a formular un plan económico-financiero si se le permitieran aplicar soluciones que no perjudiquen sus cuentas como la creación del fondo previsto en el artículo 13. 4 LBRL para los supuestos de fusión.

\section{UNA REFLEXIÓN FINAL}

El legislador estatal optó por reformar el artículo 13 LBRL para intentar corregir algunos de los problemas que suscita nuestra planta municipal. Sin embargo, el análisis de los cambios introducidos pone de manifiesto su limitado alcance. La exigencia de un núcleo de población de al menos 5.000 habitantes para la creación de un nuevo municipio por segregación sí puede tener consecuencias efectivas. Se trata de un requisito objetivo y fácil de contrastar, frente a otros de más sutil apreciación. Puede así frenarse la tendencia de algunas Comunidades Autónomas que no han dudado en crear nuevos municipios en los núcleos de población previamente constituidos como Entidades locales de ámbito territorial inferior al municipio con población significativamente inferiores. Algo de positivo habrá surgido de la reforma. Pero no parece que la nueva regulación de las fusiones voluntarias de municipios sea seguida por muchos municipios, ni siquiera de aquellos que están inmersos en procesos de saneamiento económico. Y eso a pesar de lo que el legislador estatal ha confiado en el convenio de fusión. De todo ello cabe concluir que la LRSAL también en este plano fue una reforma precipitada, motivada por una perspectiva estrictamente económica y sin valorar otras posibles soluciones que había puesto de relieve la doctrina. Así se ha señalado, por ejemplo, con la posible incorporación del municipio no sostenible económicamente a otro financieramente saneado.

Por lo anterior, no parece previsible que se produzca una reducción significativa de municipios ni por la aplicación del convenio de fusión del artículo 13 LBRL ni por la formulación de propuestas en tal sentido en el plan económico-financiero del artículo 116 bis LBRL. A lo sumo, se habrá conseguido que no se creen nuevos municipios por segregación. No obstante, esto no significa que no existan soluciones. Haberlas haylas.

\section{BIBLIOGRAFÍA}

ALMEIDA CERREDA, M.: "La fusión convencional de municipios: una institución introducida por la Ley 27/2013, de 27 de diciembre, y consagrada por la Sentencia del Tribunal Constitucional 41/2016, de 3 de marzo", en Estudos em homenagem ao Professor Doutor António Cândido de Oliveira, coordinado por C. S. MELO FIGUEIRAS, I. C. MONTEIRO FONSECA, J. FREITAS DA ROCHA y P. MADEIRA FROUFE, Livraria Almedina, Coimbra, 2017.

- "Un nuevo instrumento para el redimensionamiento de la planta municipal española: el convenio de fusión entre ayuntamientos", en Istituzioni del federalismo: rivista di studi giuridici e politici, núm. 2, 2015.

- "La planta local a pequeña escala: municipios y entidades locales menores", en Cuadernos de Derecho Local, núm. 35, 2014.

ALONSO MAS, M. a J.: "El nuevo régimen de las fusiones de municipios", en Reforma del Régimen Local. La Ley de Racionalización y Sostenibilidad de la Administración Local: veintitrés estudios, coordinada por M. J. DOMINGO ZABALLOS, Thomson Reuters Aranzadi, Cizur Menor (Navarra), 2014.

ÁLVAREZ MONTOTO, J.: "La Incidencia de la Ley de Racionalización y Sostenibilidad de la Administración Local en la planta local española. La fusión voluntaria de municipios”, en Revista de Estudios Locales. Cunal, núm. 173, 2014.

AMENÓS ÁLAMO, J.: "El elemento territorial del municipio en la Ley 27/2013, de Racionalización y Sostenibilidad de la Administración Local", en Anuario de Gobierno local 2013, 2014.

ANTELO MARTÍNEZ, A. R.: "Fusiones de municipios: ¿prevalencia del derecho estatal en el régimen de adopción de acuerdos?. Especial referencia al caso de los municipios de Ozas y cesuras en la provincia de A Coruña", en Revista de Estudios Locales. Cunal, núm. 155, 2013. 
REALA. Nueva Época - N. ${ }^{9}$, Abril 2018 - ISSN: 1989-8975 - DOI: 10.24965/reala.v0i9.10513 - [Págs. 5-21]

La alteración de términos municipales en la reforma local de 2013: crónica de un fracaso anunciado

Eloísa Carbonell Porras

ARIAS MARTÍNEZ, M. ${ }^{a}$ A.: "La fusión de municipios", en La racionalización de la organización administrativa local: las experiencias española, italiana y portuguesa, dirigida por M. ALMEIDA CERREDA, C. TUBERTINI y P. GONÇALVES, y coordinada por D. Santiago IGLESIAS, F. DI LASCIO y P. CRUZ E SILVA, Civitas Thomson Reuters, Cizur Menor (Navarra), 2015.

ARROYO YANES, L. M.: "La creación de municipios en el nuevo derecho de la Administración Local”, en Libro homenaje al profesor Rafael Barranco Vela, coordinado por F. BALAGUER CALLEJÓN y E. ARANA GARCÍA, 2014.

BAYONA I ROCAMORA, A.: "La Ley de Racionalización y Sostenibilidad de la Administración Local y el Tribunal Constitucional: comentarios a las primeras sentencias", en Cuadernos de Derecho Local, núm. 4, 2017.

BOIX PALOP, A.: "El régimen local tras el fracaso de la reforma 2013", en El cronista del Estado Social y Democrático de Derecho, núm. 68, 2017.

BUSTILLO BOLADO, R. O.: "Los convenios", en Tratado de procedimiento administrativo común y régimen jurídico básico del sector público, coordinado por E. GAMERO CASADO, Tirant lo Blanch, Valencia, 2017.

CARBONELL PORRAS, E.: "Sobre la reforma local y las competencias municipales propias", en Revista Vasca de Administración Pública, núms. 99/100, número especial en recuerdo y homenaje al Profesor Demetrio Loperena, 2014.

- "Replanteamiento sobre las provincias: del pretendido reforzamiento de su posición institucional a una posible mutación constitucional", en Anuario del Gobierno Local 2015/16, 2016.

- "La planta local: análisis general y perspectivas de reforma", en La planta del Gobierno Local, coordinadas por J. J. DÍEZ SÁNCHEZ, Fundación Democracia y Gobierno Local, Barcelona, 2013.

- "La Administración local en el Estatuto de Autonomía de 2007 y en la reciente legislación andaluza", en Tratado de Derecho Municipal, dirigido por S. MUÑOZ MACHADO, Madrid, lustel, 2011.

CALONGE VELÁZQUEZ, A.: "La fusión de municipios, único instrumento de la Ley 27/2013, de 27 de diciembre, de racionalización y sostenibilidad de la Administración Local para la modificación de la planta municipal: una oportunidad perdida", en Revista de Estudios de la Administración Local y Autonómica núm. extraordinario enero 2015. DOI: https://doi.org/10.24965/reala.vOiextra.10222.

CASTILLO BLANCO, F. A.: "La reforma de los Gobiernos Locales en España. ¿Una oportunidad perdida para lograr una planta local competitiva y sostenible?", en Memorial para la reforma del Estado. Estudios en homenaje al profesor Santiago Muñoz Machado, coordinado por José M. ${ }^{a}$ BAÑO LEÓN, CEPC, II, Madrid, 2017.

CORCUERA TORRES, A.: "Aspectos financieros de la reforma local", en Revista de estudios de la Administración Local y Autonómica, núm. Extraordinario 2015. DOI: https://doi.org/10.24965/reala.vOiextra.10224.

COSCULLUELA MONTANER, L.: "Reforma de la Administración Local. Una oportunidad de modificar la planta municipal que no puede perderse", en Revista Española de Derecho Administrativo, núm. 157, 2013.

- "Presentación", en Crisis económica y reforma del régimen local, coordinada por L. COSCULLUELA MONTANER y L. MEDINA ALCOZ, Civitas Thomson Reuters, Navarra, (Cizur Menor), 2012.

DÍEZ SÁNCHEZ, J. J.: "Estrategias para ganar tamaño en la gestión administrativa tras la reforma de 2013", en Los retos del gobierno local tras la reforma de 2013, coordinada por A. BOIX PALOP y A. M. ${ }^{a}$ de la Encarnación, Thomson Reuters Aranzadi, 2015.

DE DIEGO GÓMEZ, A.: "Las fusiones de ayuntamientos", en El Consultor de los Ayuntamientos y de los Juzgados, núm. 5, 2014.

- "Las fusiones de ayuntamientos", en La reforma del Régimen Jurídico de la Administración Local. El nuevo marco regulatorio de la Ley de racionalización y sostenibilidad de la Administración Local, coordinada por J. A. CARRILLO DONAIRE y P. NAVARRO RODRÍGUEZ, La Ley-El Consultor de los Ayuntamientos, Madrid, 2014.

- "La fusión de Ayuntamientos con especial referencia a Galicia", en Revista Gallega de Administración Pública núm. 47, 2014.

DÍAZ LEMA, J. M.: "La STC 041/2016: aval del Tribunal Constitucional a las medidas relativas a la planta local y la reordenación de las competencias locales de la Ley 27/2013, de 27 de diciembre", en Revista Española de Derecho Administrativo, núm. 181, 2016.

- "La proyección del principio de sostenibilidad financiera sobre el marco competencial y la reordenación del «mapa» local (Ley 27/2013, de 27 diciembre)", en Sostenibilidad financiera y Administración local. Un estudio comparado, coordinada por J. M. DÍAZ LEMA, Tirant lo Blanch, Valencia, 2014.

DURÁN GARCÍA, F. J.: La fusión de municipios como estrategia, Dykinson, 2016.

- "La fusión coactiva de municipios en España: principios, estrategia y resultados", en El Cronista del Estado Social y Democrático de Derecho, núm. 57, 2016.

GALÁN GALÁN, A.: "La aplicación autonómica de la Ley de Racionalización y Sostenibilidad de la Administración Local", en Revista de Estudios de la Administración Local y Autonómica, núm. extraordinario 2015. DOI: https:// doi.org/10.24965/reala.vOiextra.10225.

GOSÁLBEZ PEQUEÑO, H.: "Los convenios administrativos", en Innovaciones en el procedimiento administrativo común y el régimen jurídico del sector público, dirigida por F. LÓPEZ MENUDO, Editorial Universidad de Sevilla, Sevilla, 2016.

GRACIA HERRERO, F. J.: "La racionalización de la estructura organizativa en los pequeños municipios tras la reforma local", en El Consultor de los Ayuntamientos y de los Juzgados, núm. 5, 2014. 
GRACIA RETORTILLO, R.: "La LRSAL ante el Tribunal Constitucional: la afectación a la autonomía local”, en Anuario del Gobierno Local 2015/2016, 2016.

HERNANDO RYDINGS, M.: "La colaboración interadministrativa local: novedades en el nuevo régimen jurídico de los convenios y de los consorcios", en El nuevo procedimiento administrativo local tras la Ley 39/2015, dirigida por C. CAMPOS ACUÑA, Wolters Kluwer, Madrid, 2016.

JIMÉNEZ BLANCO, E.: "La fusión de municipios en la Ley de racionalidad y sostenibilidad de la Administración Local”, en Análisis de las repercusiones de la reforma local sobre la organización, competencias y servicios de las entidades locales, dirigida por F. GARCÍA RUBIO, INAP, Madrid, 2015.

MARTÍN REBOLLO, L. y ALEGRE ÁVILA, J. M.: "Las competencias locales en la STC 41/2016, de 3 de marzo", en Los retos del Estado y la Administración en el siglo XXI. Libro homenaje al profesor Tomás de la Quadra-Salcedo Fernández del Castillo, coordinado por L. PAREJO ALFONSO y J. VIDA FERNÁNDEZ, Tirant lo Blanch, Valencia, II, 2017.

MARTÍNEZ DE LA CASA RODRÍGUEZ, E.: "Vetos y resistencias en el fracaso de la reforma de la planta local en España", en Revista de Estudios de la Administración Local y Autonómica, núm. 5, 2015, p. 120 y ss.

MEDINA ALCOZ, L.: "La distribución de competencias entre el Estado y las Comunidades Autónomas a la luz de las sentencias constitucionales sobre la reforma local de 2013", en Anuario del Gobierno Local 2015/2016, 2016.

MEDINA GUERRERO, M.: La reforma del régimen local, Tirant lo Blanch, Valencia, 2014.

MELLADO RUIZ, L.: Génesis y realidad de la Ley 27/2013, de 27 de diciembre, de Racionalización y Sostenibilidad de la Administración Local: ¿una nueva reforma económica local?, CEMCI, Granada, 2014.

- "Crisis económica y Administración local" en Crisis económica y Derecho Administrativo. Una visión general y sectorial de las reformas implantadas con ocasión de la crisis económica, dirigida por A. EZQUERRA HUERVA, Thomson Reuters Aranzadi, 2016.

PADRÓS REIG, C.: "El examen de la constitucionalidad de la reforma local de 2013", en Revista General de Derecho Administrativo, núm. 46, 2017.

PALOMAR OLMEDA, A.: "La supresión-fusión de municipios", en Cuadernos de Derecho Local núm. 37, 2015.

PAREJO ALFONSO, L.: "Algunas reflexiones sobre el impacto de la Ley 27/2013, de 27 de diciembre, sobre el modelo de autogobierno local" en Cuadernos de Derecho local, núm. 34, 2015.

PIZARRO NEVADO, R.: "Entidades y «entes» de ámbito territorial inferior al municipio tras la reforma local de 2013", en Revista de Estudios de la Administración Local y Autonómica núm. 8, 2017. DOI: https://doi.org/10.24965/reala. v0i8.10437.

— "Disposiciones generales, principios de actuación y funcionamiento del sector público", en El nuevo régimen jurídico del sector público, dirigida por H. GOSÁLBEZ PEQUEÑO, Wolters Kluwer, Madrid, 2016.

- "Significación y claves de la Ley de Régimen Jurídico del Sector Público", en Revista Gallega de Administración Pública, núm. 53, 2017.

PONS-PORTELLA, M.: "La población mínima de los nuevos municipios: estado de la cuestión tras la Ley de Racionalización y Sostenibilidad de la Administración Local", en Revista de Estudios de la Vida Local y Autonómica, núm. 5, 2016. DOI: https://doi.org/10.24965/reala.v0i5.10353.

REBOLLO PUIG, M.: "En busca de la prevalencia perdida", en Memorial para la reforma del Estado. Estudios en homenaje al profesor Santiago Muñoz Machado, coordinado por José M. a BAÑO LEÓN, CEPC, Madrid, 2017.

- "La supresión de los pequeños municipios: régimen, alternativas, ventajas e inconvenientes", en Revista de estudios de la administración local y autonómica, núm. 308, 2008. DOI: https://doi.org/10.24965/reala.v0i308.9701.

REBOLLO PUIG, M. y CARBONELL PORRAS, E.: "La Administración local en la legislación andaluza", en Tratado de Derecho Municipal, dirigido por S. MUÑOZ MACHADO, Civitas, Madrid, 2003.

REBOLLO PUIG, M. y PIZARRO NEVADO, R.: "Las Entidades Locales Autónomas”, en Revista Andaluza de Administración Pública, núm. 42, 2001.

SANTIAGO IGLESIAS, D.: "Debate sobre la fusión de municipios en España: balance histórico y estado actual de la cuestión", en Estudos em homenagem ao Professor Doutor António Cândido de Oliveira, coordinado por C. S. MELO FIGUEIRAS, I. C. MONTEIRO FONSECA, J. FREITAS DA ROCHA y P. MADEIRA FROUFE, Livraria Almedina, Coimbra, 2017.

SANZ LARRUGA, F. J.: "De la segregación a la fusión de municipios en España", ambos en Libro homenaje al profesor Rafael Barranco Vela, coordinado por F. BALAGUER CALLEJÓN y E. ARANA GARCÍA, 2014.

TEJEDOR BIELSA, J.: "El desarrollo autonómico de la reforma local de 2013. Entre la rebelión y el pragmatismo", en Los retos del gobierno local tras la reforma de 2013, coordinada por A. BOIX PALOP y A. M. ${ }^{a}$ de la Encarnación, Thomson Reuters Aranzadi, 2015.

VILLAR ROJAS, F.: "Razones y contradicciones de la Racionalización y Sostenibilidad de la Administración Local" en La administración al día, INAP, 18 de julio de 2014. 